\title{
ACHIEVING THE MDGs - A NOTE ${ }^{35}$
}

\author{
Naill Kishtany and Alemayehu Seyoum Taffesse ${ }^{36}$
}

\begin{abstract}
The material and symbolic importance of the MDG targets make it vital to assess the analytical coherence of the MDG "project". In this spirit, this note highlights complexities and difficulties of the MDG approach that policy makers should consider. It covers issues of measuring progress, and achieving and valuing outcomes; sustaining outcomes; devising policies during structural transformation; and implementing policies in a decentralised policy system. These discussions draw attention to some of the limitations of current methods of analysing the MDGs. A final section concludes.
\end{abstract}

\footnotetext{
35 The bulk of this note was prepared for a report to UNICEF in 2004. In fact, its key elements were presented to a seminar at the UNECA even earlier (in early 2003, to be specific). We believe that it is relevant today to highlight the difficulties of the MDGs perspective. We thus made only very minor changes to the text.

${ }^{36}$ Alemayehu Seyoum Taffesse is currently a Research Fellow at the Washington-based International Food Policy Research Institute (IFPRI). In the last few years, he worked as an assistant professor of economics at Addis Ababa University, an economic affairs officer at the United Nations Economic Commission for Africa, and the director of the African Centre for Economic and Historical Studies (an independent research outfit in Addis Ababa that he established in 2004). His research interests span individual aspirations and wellbeing, impact evaluation of government programs, household risk and vulnerability, government policy and agriculture, and economic governance in Ethiopia as well as more broadly. Alemayehu holds a D.Phil (or Ph.D.) degree in Economics from the University of Oxford.
} 


\section{Introduction}

The Millennium Development Goals (MDGs) are a set of internationally agreed targets that poor countries aspire to attain by 2015. The eight broad MDGs (as well as the corresponding targets and indicators) span poverty reduction, primary education, gender parity, child mortality, maternal mortality, reversal of diseases, environmental sustainability, and development cooperation.

The MDGs are fast becoming the touchstone for directing as well as assessing socioeconomic progress across the developing world. Increasingly, country-level policy frameworks such as Poverty Reduction Strategies (PRSs) are linked to the MDG targets; estimates are now being made of the aid flows required to achieve the MDGs. Crucially, the MDGs can be a useful focal point for social and political dialogue and action in both poor and rich nations towards improving the lot of the poor around the globe.

The material and symbolic importance of these targets make it vital to assess the analytical coherence of the MDG "project". In this spirit, this note highlights complexities and difficulties of the MDG approach that policy makers should consider. Section two sets out an analytical framework for analysing the MDGs. The following four sections cover issues of measuring progress, and achieving and valuing outcomes; sustaining outcomes; devising policies during structural transformation; and implementing policies in a decentralised policy system. These discussions draw attention to limitations of current methods of analysing the MDGs. A final section concludes and proposes a more sophisticated and tractable approach to the MDGs.

\section{Conceptualising the MDGs as a policy "problem"}

The MDGs are a set of time-bound, multi-dimensional socio-economic goals almost all of which can in principle be translated into quantifiable targets and indicators ${ }^{37}$ Development policy practitioners commonly believe that there are policy levers which governments can use to move countries towards achievement of these targets.

Ideally, the "solution" to a policy "problem" then consists of setting instruments' values so as to hit the targets, while allowing for institutional changes, uncertainty, and some learning. In mathematical terms, Tinbergen's rule states that well-defined solutions in a static framework require that the number of instruments equals or exceeds the

\footnotetext{
${ }^{37}$ There are eight overall goals some of which contain a number of specific targets. There are a total of 18 targets.
} 
number of targets ${ }^{38}$, (Tinbergen (1952)). But economies are dynamic not static systems; policy makers therefore seek to control the evolving system at a point in time (point controllability) and to influence its trajectory over time (path controllability). In this dynamic perspective, Tinbergen's rule no longer holds for point controllability because rates of change of instruments as well as their absolute levels can affect objective variables.

But for many policy purposes-including the MDGs-path controllability is the measure of success: policy makers want not just the instantaneous achievement of targets but that these are sustained over time and arrived at by a path that strays as little as possible from politically and economically acceptable values of instruments and objectives. Path controllability, a stricter requirement than point controllability, in many cases does in fact require that the number of instruments equals or exceeds the number of targets (Petit (1990)). For a set of instruments and objectives this is in part conditional on a given structure of the economy, known outcome targets, and well-defined instruments. In practice, most policy problems do not meet the conditions for straightforward solution for the following reasons:

\section{Available policy levers and feasible values:-}

1. The number of objectives often exceeds the number of available instruments. This means that a "solution" does not exist in a static system or for path controllability in a dynamic system.

2. There may be more than one solution when the number of instruments exceeds the number of targets.

3. Even if a solution does exist, the values of the instruments needed to achieve it may be politically or technically infeasible.

\section{Interdependencies:-}

4. Some objectives may be related. They may be complementary, or they may be contradictory and raise policy trade-offs.

5. Some instruments may be related. Again, they may be complementary or contradictory.

6. Different instruments may be controlled by different policy institutions leading to problems of coordination and conflict.

\section{Causality, information and uncertainty:-}

\footnotetext{
${ }^{38}$ More precisely, the number of linearly independent instruments must be equal or greater than the number of linearly independent targets (Petit (1990)).
} 
7. There may be uncertainty about the relationships between instruments and objectives, or even about what the instruments are.

8. Some variables may be either instruments or objectives depending on the context or level of analysis (and whether analysis takes a static or dynamic perspective).

9. Information on the actual values of instruments and targets may be imperfect. 10. The structure of the economy may change over time. It may be affected by movements in instruments and target variables. In turn, as it evolves the extent to which (1)-(9) hold may change.

All of these problems are likely to bedevil progress on the MDG project. ${ }^{39}$ In particular, they complicate attempts to measure progress towards and devise strategies for achievement of the targets; they also bring to the fore problems of valuing outcomes in multi-dimensional space (section three). They raise issues about the sustainability of outcomes (section four). In addition, they highlight complexities in devising policies during structural change where uncertainty and learning effects are critical (section five). Finally, they show the importance of coordination between different policy institutions (section six).

\section{Measuring progress and achieving outcomes}

In a static perspective, points (1) and (3)-(5) may mean that not all targets are achievable at a certain date. If the number of MDG targets exceeds the number of instruments available, then governments may not have enough levers to reach all of the targets. The interdependencies defined in (4) and (5) complicate the picture: trade-offs may frustrate the simultaneous achievement of certain targets while complementarities could offset the problem of insufficient levers defined in point (1). Even if the problems identified in section two do not hold and we revert to an easily soluble policy problem, trade-offs may still be present if moving policy levers requires scarce resources: in this case if different instruments "compete" for resources, tradeoffs will be generated at the level of outcomes. In the case of MDG achievement both of these kinds of interdependencies are relevant.

The interaction between levers and targets takes place over time; the static problems contained in (1)-(6) have dynamic counterparts. Points (1) and (3)-(5) mean that a desired path of objectives and instruments may not be feasible. (4)-(6) imply that there may be varying speeds of progress towards different targets. Point (8) adds to this, but in a dynamic sense suggests a further complexity in the achievement of multiple targets. Instruments and outcomes may need to be sequenced over time:

\footnotetext{
${ }^{39}$ These problems are also likely to be significant for domestically-driven planning initiatives.
} 
certain values of instruments may be required for certain values of other instruments later on; the same may apply to outcomes. Whether variables are instruments or objectives then changes over time. There may be a complex, shifting pattern of variables' status as means or ends. Point (10) is an explicitly dynamic problem which reinforces this point; indeed, one would hope that the structure of the economy would change as development takes place (see section five).

\section{Interdependencies: examples from the MDGs}

Trade offs- The large number of targets in the MDGs reflects the now established view of development as a multi-dimensional process. This breadth means that the problem of interdependence is likely to bite. There may be direct trade-offs at the level of outcomes. For example, some aspects of environmental sustainability (Goal 7) could conflict with the eradication of extreme poverty and hunger (Goal 1) within certain time frames. This would be so if the livelihoods of some segments of the poor depend on the exploitation of natural resources such as forests or minerals in ways which conflict with the goal of long-term environmental sustainability.

There may also be trade offs between instruments leading to policy conflicts over outcomes. For example, economic growth is a key instrument for reaching a range of targets, including, for example, universal primary education (Goal 2), the achievement of which calls for considerable resources best generated through output expansion. Cutting poverty requires growth but can also be achieved by reducing inequality through redistributive policies; the relative effectiveness of these two routes depends on certain underlying structural parameters of the economy (Dagdeviren et. al. (2000)).

The relationship between these two instruments - growth and inequality reduction and/or redistribution - has been the subject of a long debate in economics. In the $20^{\text {th }}$ century this was carried forward through the work of Simon Kuznets who argued for a positive relationship between growth and inequality, at least in the early stages of development (Kuznets (1966)). If this is so, then there could be a trade off between these two critical instruments; this could lead to trade offs at the level of the objectives mentioned. ${ }^{40}$

Indirect trade-offs in outcomes because of competition for resources between instruments are present in the MDGs. The MDG targets reflect the expansion of policy from the narrow macroeconomic stability objectives of the 1980s into

\footnotetext{
${ }^{40}$ More recently, a literature has emerged claiming a positive relationship between equality and growth, some of this based on analysis of the East Asian experience (Birdsall et. al. (1995); Alesina and Perotti (1994)). This has led to a new consensus which emphasises the growth-dampening effects of inequality. Nevertheless, the linkages between distribution and growth are complex and still little understood. Indeed, some have questioned the East Asian evidence purporting to show a positive relationship between equality and growth, arguing that many studies make cavalier use of inequality data (Moll (1992)).
} 
interventions designed to directly affect social outcomes in health, education, the environment and gender relations, all now common ingredients of PRSs. A range of instruments are used to improve results in these areas. Many of these are not directly contradictory, but nearly all call for considerable funds. This implies outcome trade offs in countries carrying out PRS-driven expenditures: these countries often have small resource bases, high fiscal deficits and external debt burdens, and necessarily finite inflows of concessionary finance. Here, difficult choices may need to be made between, for example, technology investments to improve environmental sustainability and hygiene programmes for mothers to bring about the targeted reduction in child mortality (Goal 4).

Complementarities- On the other hand, it is now recognised that many of the instruments and objectives contained in the MDGs are complementary. In the objectives, female education (part of Goal 3) reduces child mortality through better nutritional and caring practices by mothers as a result of enhanced literacy and skills. Improved maternal health (Goal 5) is also likely to help reduce child mortality. Clearly, reversing the spread of epidemics such as malaria and HIVIAIDS will cut mortality. In turn, better outcomes in education and gender equality should help to halt the spread of these diseases, particularly HIVIAIDS. Finally, better educational and health outcomes should reduce poverty, directly, by enhancing poor people's entitlements to essential services and indirectly, through poverty-reducing growth as emphasised in "new" growth theories.

Sequencing - This analysis suggests that the problem of sequencing will complicate achievement of the MDGs. In particular, the kinds of complementarities described may unfold over time as part of a complex cycle of socio-economic transition. For example, low inequality is now considered an important aspect of East Asia's spectacular socio-economic performance. One view of developmental success in East Asia sees both low inequality and good educational outcomes as the essential initial conditions for subsequent high growth and poverty reduction (see McMahon (1998 on education; Birdsall et. al. (1995 on inequality and education). Using our division of variables into MDG targets and policy levers, certain values of instruments (distribution patterns) and objectives (education) may have been pre-requisites for later values of both instruments (growth) and objectives (poverty reduction). At a more micro level, improving gender equality is likely to be a prerequisite for halting and reversing the spread of HIVIAIDS (part of Goal 6). Thus, some variables may start as objectives but later be instruments for the achievement of other objectives.

\section{Measurement problems}


We have seen how interdependencies complicate strategies for achieving the MDGs, here conceptualised as a mapping from instruments to objectives. Trade-offs and complementarities also mean that measuring progress towards the targets in terms of movements in the values of objectives and instruments may necessitate more sophisticated analytical frameworks than those currently used. Benchmarking methods in their simplest but common form measure progress by extrapolating past rates of change for each target individually to see if the country in question is "on course" (Devarajan et. al. (2002); Sahn and Stifel (2001)). Clearly this is a highly imperfect approach if interdependencies and sequencing requirements are present. In such situations, measurement needs to take into account of interdependencies at the level of both objectives and instruments to give a more comprehensive picture of countries' distance from the targets.

Measurement is also hampered by imperfect information about the actual values of instruments and variables (point (9)). This is especially so because the MDG targets encompass a broad range of variables, including "soft" social indicators. In addition, interdependencies mean that the data problems of certain targets and instruments may lead to difficulties in the assessment of related variables. Imperfections in data sets essential for measurement of MDG outcomes and instruments including those for income, inequality, poverty and health status are well known. Even for developed economies, data sets such as those for inequality need to be handled with caution (Atkinson and Brandolini (2001)); in poor countries where statistical capacity is limited this is even more critical (Srinivasan (1994)).

\section{Valuing outcomes}

"Progress" implies valuation; in multi-dimensional space this is not straightforward. If interdependencies-particularly trade offs-along with the requirements of sequencing mean that not all goals can be achieved simultaneously, then social weightings will be needed to arbitrate between targets. This suggests the need for a social welfare function defined across the targets with explicit weights assigned to each objective. How such weightings would be determined is a complicated political as well as economic problem outside of the scope of this paper.

However, if choices do need to be made it would be better to make them explicitly rather than by ad hoc means or in reaction to uncontrollable events. Current methods of assessment do not fully acknowledge this and fail to take a systematic social welfarist approach to the problem. Defining a social welfare function is a complex task but opens up solutions to many of the problems flowing from the MDGs' formulation as a set of fixed targets. This is discussed further in section seven. 


\section{Sustaining outcomes}

Point (7) in its dynamic form frames the problem of sustainability when targets begin to be achieved. Sustainability is a kind of path controllability: policy makers at a minimum want the economy's trajectory to preserve the values of objective variables once targets are hit. But shifting policy levers requires resources; given the limited resource base of developing countries much of this will be in the form of external inflows, whether overseas development assistance or loans. What is the long term relationship between instruments and outcomes and how stable are shifts in their values? If a certain value of an instrument-partly achieved through an infusion of external funds-leads to the realisation of a target, how permanent is this state and what is required to sustain it? Does the value of the instrument need to be sustained to preserve achievement of the target? If so, for how long will aid be needed to sustain the value of the instrument?

This is important for two reasons. Firstly, movement towards the MDG targets is supposed to be equivalent to a shift towards a higher level of development. Historically, long term development in successful countries has been propelled by a self-sustaining process of internal transformation, even if external funds have acted as a catalyst or secondary engine. Successful development involves countries becoming self-sufficient in the sense of not requiring concessional aid to plug resource gaps. One would hope, therefore, that achievement of the MDGs on the basis of certain kinds of relationships between instruments and objectives is part of a self-sustaining development cycle and not merely the "artificial" attainment of targets through large financial inflows divorced from underlying processes of internal transformation. Secondly, there is a danger that once targets are achieved, donors' attention may turn elsewhere in the belief that development problems are "solved". Sustainability may be hard to achieve (Kremer and Miguel (2004)); if aid is required after the targets are met, then this needs to be made explicit.

Two of the MDGs relate to education and centre on rates of enrolment; they illustrate the problem of sustainability. Enrolment rates are determined by supply and demand factors. Supply relates to the number of schools and their distance from communities and is partly a function of resources allocated to the educational sector. Demand for schooling is influenced by the private rate of return to education determined by the difference in earnings of workers with varying levels of education. Clearly, then, educational outcomes are a function not just of provision, but also of the extent of income earning opportunities for skilled workers generated by economic growth and a changing sectoral composition of output. Studies have shown that the availability of 
schooling and state expenditure on education do not very well explain enrolment rates (Bredie and Beeharry (1998); Lavy (1996)).

Much analysis of the MDGs' educational targets focuses exclusively on the supply side and on the amount of state resources that need to be spent calculated on the basis of an educational unit cost and the number of students not enrolled (for an example see Devarajan et. al. (2002)). Given the importance of demand-side factors in educational outcomes, this bias raises questions regarding the sustainability of targets in the way that we have defined it. In Indonesia, for example, enrolment rates were boosted during the 1970s and 1980s by demand-side factors caused by fast economic growth, and by an expansion of supply as a result of a large school-building programme. However, the economic crisis of the 1990s brought a sharp reversal in these gains. A similar trajectory was seen in Botswana when enrolment fell from a high level over the 1990s because of the HIVIAIDS crisis (Clemens (2004)).

Sustainability problems come in a slightly different guise in countries which have seen rapid rises in enrolment, but with significant deteriorations in quality as measured by the ratio of teachers to pupils, exam performance and repetition rates (see World Bank (2002) for evidence on Uganda; World Bank (2003) on Rwanda). Here, though, if enrolment outcomes are adjusted for quality, it may be that many of these countries have not made significant gains. But increasing enrolment through lowering quality may still raise issues of sustainability in our meaning of the term if declining quality reduces the private returns to education thereby choking off demand for schooling.

Standard benchmarking approaches, which take little account of interactions between variables and therefore the underlying drivers of progress, fail to address the requirement of sustainability. These methods, being anchored in the MDGs' 2015 timeframe, use the criterion of point controllability. They would therefore give little warning of future reversals of the kinds discussed.

\section{Structural transformation and "qualitative" policy design}

So far analysis has been in terms of a "quantitative" policy problem: we have considered the relationships between instruments and targets while assuming that the underlying structure of the economy stays constant. But point (10) is important in developing countries where policy is typically aimed at changing deep structural parameters of the economy. Qualitative or structural policy focuses not on the values of target variables but on the relationship between variables (Eggertsson (1997)). It seeks to induce new relationships between existing instruments and targets and to 
activate new policy levers. These changes then require a revised quantitative policy because the evolving system needs to be managed on the basis of new parameters.

This distinction is relevant for developing countries seeking to reach the MDGs. Development is a process of structural transformation; following the Washington Consensus there is greater understanding of the broad range of structural changes needed for successful economic performance including at the level of markets, and in economic and political institutions (Stiglitz (1998)). So although the MDGs' set of fixed targets seems to point towards a qualitative policy problem, their achievement also requires attention to the qualitative aspects of policy. As economies move towards the MDG targets, structural shifts generate an ever-changing quantitative policy problem as new instruments and relationships come into play. This is related to the problem of sequencing discussed in section three: an evolving set of instruments may need to follow a certain time path if some are prerequisites for others.

To give some examples from the MDGs, gender empowerment may alter the functioning of labour markets, leading to shifts in the labour supply function as more women are able to work. This could lead to new relationships between growth, employment and poverty reduction. Institutional reform involves the emergence of new patterns of economic and political control which fundamentally change the operation of the economic system. An important component of this, governance reform - now a central part of developing countries' policy packages - is in part aimed at improving service delivery. Success in this area could change the relationship between public spending on health and education and outputs in these sectors. As countries reach certain stages of development, it is said that the decentralisation of some policy levers to regional governments can be good for government efficiency and service delivery. This is an example of a qualitative policy shift which gives rise to new instruments and relationships between instruments and objectives. Other important types of institutional change in developing countries are the transfer or sharper delineation of property rights and the formalisation of informal sectors of the economy, both of which may activate new instruments and bring new mappings between instruments and objectives.

The distinction between qualitative and quantitative policy shows just how complex the policy problem is for developing countries, especially in attaining a broad set of targets such as the MDGs. Structural changes often take place during times of political and social instability, common features of developing countries. Policy analysis therefore needs to take into account of political and social factors and likely conflict and contestation as new structures emerge, triggering new relationships between instruments and objectives. 


\section{Uncertainty and learning}

Points (7), (9) and (10) are prominent in the MDG policy problem because of the importance of structural change in developing economies. When uncertainty exists over the parameters of the model describing the economy, policy decisions are dependent on the statistical distribution of these parameters. In this case we need to consider learning effects as instruments and objectives move over time; policy making then becomes a drawn out process of discovery.

In a situation of passive learning, policy makers' estimates of the economy's structural parameters change as new information emerges. Under active learning, this updating takes place as a direct result of policy makers' manipulation of instruments which allows them to discover more about the behaviour of the system (Kendrick, 2002; Petit 1990). Policy actions then have a dual purpose of bringing the economy closer to the desired path and reducing uncertainty about the operation of the system. Under active learning there may be a trade off between system performance and learning: certain policy actions may lead to a worse system performance at a point in time compared to others but yield better information about the operation of the economy, helping to give rise to better outcomes in the long run.

Active learning is critical if there is large uncertainty about the parameters of the economy or when the economy is going through structural change. Both come into play in the MDGs: there is clearly much uncertainty about the causal mechanisms of developing economies while development itself is a process through which the economy undergoes structural evolution equivalent to changes in underlying parameters. Important questions therefore surround the ability of governments to use new information to refine their policy making so as to move closer towards the MDGs. Critical parameters, new information on which may emerge as the economy moves through time, include the elasticity of poverty with respect to growth, the cost of increases in the HIV prevalence rate in terms of growth and the incremental effect of higher female educational levels on child mortality rates.

All of these will be important in finding a mapping from instruments to objectives to move more rapidly towards the goals. Making good use of such new information depends on the capacity of government institutions to analyse and act upon it. The process by which governments update their view of the economy because of new information is of great interest. In many developing countries processing capacity is limited and needs to be strengthened.

\section{Decentralised policy and coordination problems}


Point (6) further muddies the policy problem. Theoretical models and practical policy discussions often assume that policy levers are controlled by a single entity, normally the state. In practice, policy agency is dispersed among a set of institutions. Each of these institutions controls a sub-set of instruments linked to certain objectives. In this context an important issue is whether instruments and objectives can be "de-coupled" so that a particular instrument can be unambiguously assigned to an objective (Mundell (1962). If this is possible then each institution can implement its own policies and an overall solution be reached, subject to the other problems discussed above.

But here points (4) and (5) come back into play. Interdependencies will generate spillovers between institutions; the instruments and objectives of one institution may affect the values of those of another. The achievement of objectives therefore depends on coordination between different institutions. These considerations underlie the move in developing countries towards integrated, multi-sectoral policies on the basis of unified frameworks such as PRSs and Medium Term Expenditure Frameworks (MTEFs). The impetus towards donor budget support rather than project-based financing has come from a realisation that different policy areas interact and need to be considered as a coherent whole with all institutions operating under the same policy framework.

The MDGs illustrate this. The objective of halving poverty is connected to a set of instruments including those relating to macroeconomic performance. These include growth rates, inflation and the fiscal balance. Some of these levers are controlled by finance ministries and others by central banks. In turn, some of them affect objectives that come under the watch of other institutions. For example, important instruments for halting the spread of HIVIAIDS are controlled by health ministries, but the fiscal policies of finance ministries influence the amount of funds going into health and therefore have a direct impact on this goal. Similar considerations apply to many of the MDG targets. The optimal management of these kinds of spillovers require complex forms of coordination which will stretch the capacity of developing countries' bureaucracies.

\section{Conclusions}

The achievement of the broad set of precise, fixed targets embodied in the MDGs through the management of complex socio-economic systems raises doubts about the feasibility of the goals. Thinking about the MDGs in terms of instruments and objectives helps frame problems of target achievement, the measurement of progress and the valuation of outcomes all of which are difficult. We have also seen that 
sustainability of the targets is an issue which is inadequately addressed in current approaches. In addition, we argued that the need for coordination between different parts of countries' policy making systems will stretch the capacity of governments.

How useful are a set of ahistorical targets?

The issues of structural change discussed in section five expose the lack of historical context surrounding the MDGs. Most of the targets are expressed as rates of change in objective variables; two important ones - the achievement of universal primary education and the elimination of educational gender disparities - are in absolute levels. A remarkable feature of the MDGs is that the same quantitative targets are applied to all countries. Many of these countries are, however, at different stages of development. Structural change and sequencing are components of the concept of a stage of development. Countries at different stages have contrasting structural characteristics and patterns of relationships between instruments and objectives; in a dynamic perspective, certain socio-economic outcomes may be prerequisites for the transition to a more advanced stage.

None of this is taken into account of in the MDGs' absolute and universal targets. At first sight the targets seem to be a level playing field for assessing and comparing countries. In fact, that they do not explicitly account for the long term dynamics of structural change tilts the field towards those countries who have built up the critical mass of internal transformations necessary for developmental take off; countries which have yet to enter this virtuous cycle are at risk of being unjustly chided in the likely event that they fail to achieve many of the goals by 2015 .

Taking a longer historical view underlines this point: in the $19^{\text {th }}$ century when today's rich nations had educational enrolment rates similar to those of today's poor countries the evolution towards high enrolment was much slower than that seen in many developing countries in recent decades. This is even the case for some developing countries which are on course to "fail" on the educational targets (Clemens, 2004). Today's rich countries only made universal primary education an explicit development goal when they had higher income levels than today's poor countries and had nearly achieved universality. If the MDGs' educational targets had been applied to today's industrialised nations during their own early stages of development, they may well have missed the targets (for similar historical evidence on some of the other targets, see Clemens et. al., 2004).

The history of today's rich countries shows that development is a drawn out, uneven and contradictory process full of reversals and discontinuity. The MDGs, with their ambitious, linear and broad set of socio-economic goals belie this complexity; 
contemporary developed countries measured yesterday with today's MDG yardstick might well have been branded "failures". 


\section{References}

Alesina, A. and Perotti, R. 1994. The Political Economy of Growth: A Critical Survey of the Recent Literature. World Bank Economic Review, Volume 8, Number 3

Atkinson, A. and Brandolini, A. 2001. Promise and Pitfalls in the Use of 'Secondary' Data Sets: Income Inequality in OECD Countries as a Case Study. Journal of Economic Literature, 39, 3

Birdsall, N., Ross, D. and Sabot, R. 1995. Inequality and Growth Reconsidered: Lessons from East Asia. World Bank Economic Review Volume 9, Number 3

Bredie, J. and Beeharry, G. 1998. School enrolment decline in Sub-Saharan Africa: Beyond the Supply Constraint. Discussion Paper 395, World Bank

Clemens, M. 2004. The Long Walk to School: International education goals in historical perspective. Working Paper Number 37, Center for Global Development

Clemens, M., Kenny, C., and Moss, T. 2004. The Trouble with the MDGs: Confronting Expectations of Aid and Development Success. Working Paper Number 40, Center for Global Development

Dagdeviren, H., van der Hoeven, R. and Weeks, J. 2000. Redistribution Does Matter: Growth and Redistribution for Poverty Reduction, mimeo.

Devarajan, S., Miller, J. and Swanson, V. 2002. Goals for Development: History Prospects and Costs, Policy Research Working Paper 2819, World Bank

Eggertsson, T. 1997. The Old Theory of Economic Policy and the New Institutionalism. World Development, Volume 25 Number 8

Elbers, Chirs , Jan Willem Gunning, and Bill Kinsey. March 2002. Convergence, Shocks, and Poverty: Micro Evidence on Growth under Uncertainty, Tinbergen Institute Discussion Paper, TI 2002-035/2, Tinbergen Institute.

Elbers, Chris, and Jan Willem Gunning. September 2003. Vulnerability in a Stochastic Dynamic Model, Tinbergen Institute Discussion Paper, TI 2003-070/2, Tinbergen Institute.

Elbers, Chris, Jan Willem Gunning, and Bill Kinsey. July 2003. Growth and Risk: Methodology and Micro Evidence, Tinbergen Institute Discussion Paper, TI 2003-068/2, Tinbergen Institute.

Fafchamps, Marcel. October 1999. Rural Poverty, Risk, and Development, Report Submitted to the Food and Agriculture Organization.

Geda, Alemayehu, and John Weeks. August 2003. Growth Instability among African Countries, mimeo.

Kendrick, David Andrew. 2002. Stochastic Control for Economic Models, Second Edition, Version 2.00. Available at http://eco.utexas.edu/faculty/Kendrick.

Kremer, M. and Miguel, E. 2004. The Illusion of Sustainability. Working Paper Number 35, Center for Global Development

Kuznets, S. 1966. Modern Economic Growth: Rate, Structure and Spread. Yale University Press

Lavy, V. 1996. School supply constraints and children's educational outcomes in rural Ghana. Journal of Development Economics, 51: 291-314

Ligon, Ethan and Laura Schechter. 2004. Evaluating Different Approaches to Estimating Vulnerability. mimeo.

McMahon, W. 1998. Education and Growth in East Asia Economics of Education Review 17(2) 
Moll, T. 1992. Mickey Mouse Numbers and Inequality Research in Developing Countries. Journal of Development Studies, Volume 28 Number 4

Mundell, R. 1962. The appropriate use of monetary and fiscal policy for internal and external stability. IMF Staff Papers, 9: 70-9.

Petit, M. 1990. Control theory and dynamic games in economic policy analysis Cambridge University Press

Sachs, Jeffrey D., John W. Mcarthur, Guido Schmidt-Traub, Margaret Kruk, Chandrika Bahadur, Michael Faye, and Gordon Mccord. 2004. Ending Africa's Poverty Trap, Brookings Papers on Economic Activity, 1: 2004.

Sahn, D. and Stifel, D. 2001. Progress Toward the Millennium Development Goals in Africa, mimeo

Srinivasan, T. 1994. Data base for development analysis: An overview. Journal of Development Economics Volume 44, pp 3-27

Stiglitz, J. 1998. More Instruments and Broader Goals: Moving toward the Post-Washington Consensus. WIDER Annual Lectures 2

Taffesse, Alemayehu Seyoum and Alex de Waal. February 2005. Child Survival during the 2002-03 Drought in Ethiopia, A Report Prepared for the United Nations Children's Fund (UNICEF) Ethiopia

Tinbergen, J. 1952. On the Theory of Economic Policy Amsterdam: North Holland.

World Bank. 2002. Achieving Universal Primary Education in Uganda: The 'Big Bang' Approach. Education Notes, Human Development Network

World Bank. 2003. Education in Rwanda: Rebalancing Resources to Accelerate Post-Conflict Development and Poverty Reduction. Report Number 26038-RW, Human Development Department, Africa Region. 